\title{
Erratum to: Optical nanoscopy
}

\section{A. Diaspro ${ }^{1,2}$ (D) P. Bianchini ${ }^{1}$}

Published online: 23 September 2020

( ) Società Italiana di Fisica 2020

\section{Erratum to: La Rivista del Nuovo Cimento https://doi.org/10.1007/s40766-020-00008-1}

After publication of the article we noticed that equations number 24 and 25 missed a convolution sign.

They should be

$$
\begin{gathered}
o(x, y, z)_{j}=i(x, y, z)_{j} \otimes s(x, y, z)_{j}+\sum_{k \neq j} i(x, y, z)_{k} \otimes s(x, y, z)_{k}+n(x, y, z) \\
o(x, y, z)_{j}=i(x, y, z)_{j} \otimes s(x, y, z)_{j}+n(x, y, z)
\end{gathered}
$$

Furthermore Fig. 7 is incorrect, please find the correct Fig. 7 here:

The original article can be found online at https://doi.org/10.1007/s40766-020-00008-1.

$凶$ A. Diaspro

diaspro@fisica.unige.it

1 Nanoscopy, CHT, Istituto Italiano di Tecnologia, Genova, Italy

2 DIFILAB, Dipartimento di Fisica, Università degli Studi di Genova, Genova, Italy 


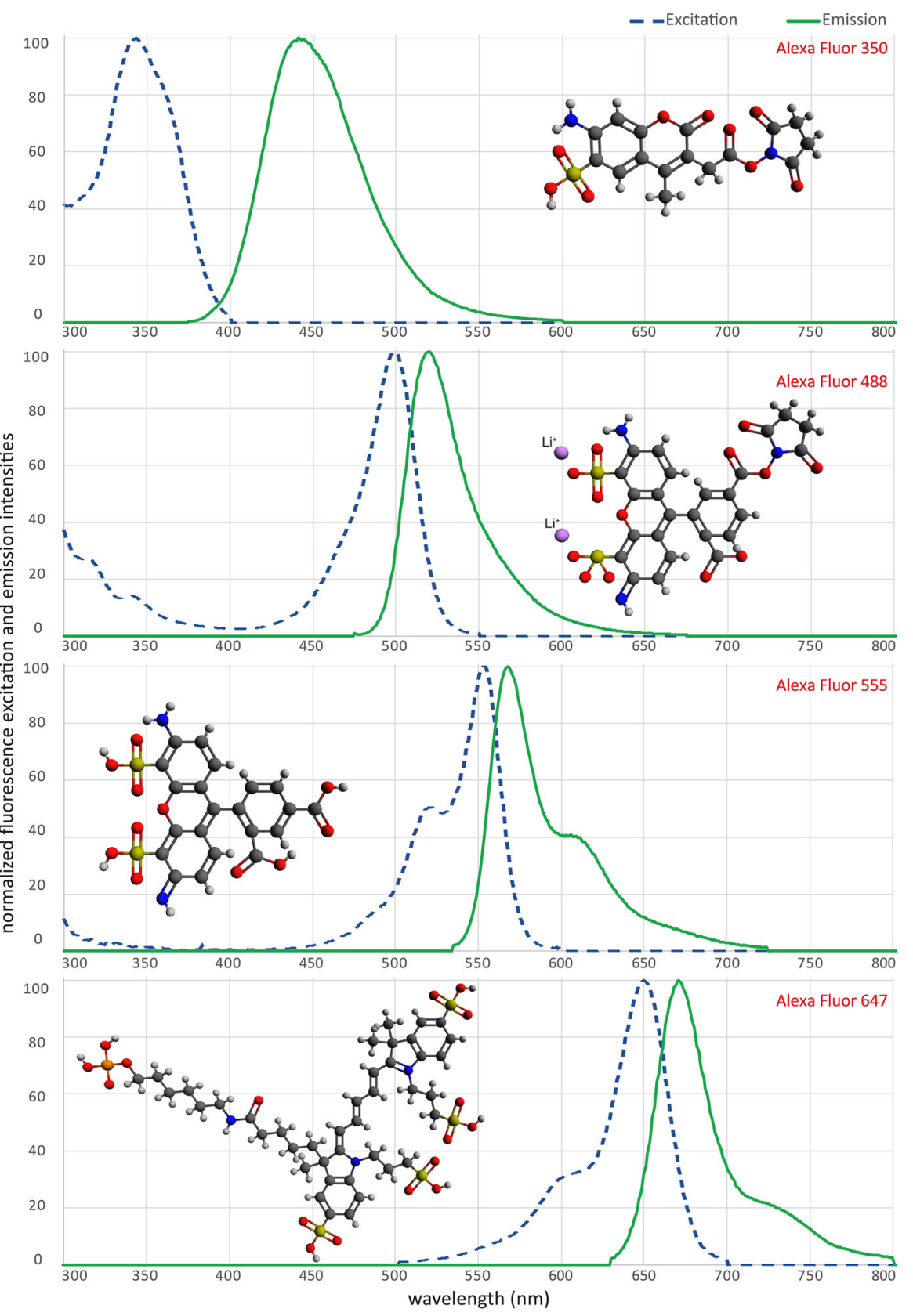

Fig. 7 Specific absorption and emission spectra of different fluorescent molecules [25] 